\title{
Dampak Kualitas, Persepsi Konsumen dan Brand Image terhadap Keputusan Pembelian Produk Endorsement
}

\author{
Lila Maria Kaban \\ Universitas Pelita Harapan \\ lila.kaban@uph.edu \\ Rifin Khong \\ Universitas Pelita Harapan \\ rifin.khong@lecturer.uph.edu
}

\begin{abstract}
Abstrak Penelitian ini bertujuan untuk melihat seberapa besar dampak kualitas produk, persepsi konsumen dan brand image terhadap keputusan pembelian produk endorsement pada masyarakat di Medan dengan menggunakan word of mouth sebagai variabel moderasi. Sampel penelitian ini adalah sebesar 100 orang responden dengan teknik analisis data menggunakan analisis jalur (path analysis). Hasil dari penelitian ini menunjukkan kualitas produk, persepsi konsumen dan brand image berpengaruh terhadap keputusan pembelian produk endorsement pada masyarakat di Medan. Lebih lanjut, word of mouth tidak memoderasi kualitas produk terhadap keputusan pembelian dan juga tidak memoderasi persepsi konsumen terhadap keputusan pembelian namun word of mouth memoderasi brand image terhadap keputusan pembelian produk endorsement bagi masyarakat di Medan.
\end{abstract}

\section{Kata Kunci Kualitas Produk, Persepsi Konsumen, Brand Image, Keputusan Pembelian, Produk Endorsement}

\section{PENDAHULUAN}

Tingginya persaingan usaha pada saat ini dapat memberikan dampak terhadap kelangsungan suatu perusahaan dan dalam menjaga kelangsungan usaha maka tugas yang paling berat adalah bagaimana perusahaan dapat mempertahankan pangsa pasar. Dalam mempertahankan konsumen perusahaan harus memiliki rencana yang mampu menghasilkan suatu strategi kompetitif dan berkesinambungan dan menghadapi para pesaing. Untuk itu perusahaan harus melakukan inovasi terhadap produk yang dihasilkan sehingga konsumen menjadi tertarik untuk melakukan pembelian terhadap sebuah produk. Salah satu bidang usaha yang paling banyak dilakukan oleh masyarakat sekarang ini adalah bisnis yang bergerak di bidang kuliner.

Usaha kuliner yang populer seperti pengolahan roti dan kue mengalami perkembangan dari tahun ke tahun dan berbagai inovasi produk baru banyak bermunculan dalam tambahan variasinya. Medan yang merupakan salah satu kota terbesar di Indonesia tentu saja memberikan keuntungan tersendiri bagi usaha roti dan kue. Ada beberapa usaha toko kue yang menjadi rekomendasi apabila datang ke kota Medan, diantaranya Toko Kue La Masion, Toko Kue Mawar Bakery and Shop, Toko Kue Clover, Toko Kue Bika Ambon Zulaikha dan masih banyak lagi. Salah satu yang menjadi fenomena sekarang ini adalah bisnis kue oleh-oleh khas daerah yang dipromosikan oleh beberapa artis ternama Indonesia. Kue yang dipromosikan oleh para artis merupakan perpaduan nuansa lokal 
dengan nuansa internasional yang bersifat modern. Dengan memberikan cita rasa yang sangat menggugah selera konsumen dan dengan di promosikannya usaha tersebut oleh para artis dapat memberikan daya tarik tersendiri kepada usaha tersebut. Yang menjadi objek penelitian ini adalah toko kue yang sering dipromosikan oleh artis / selebritu terkenal melalui kegiatan endorsement.

Faktor kualitas produk sangat penting karena dapat mempengaruhi seberapa tinggi minat beli hingga keputusan untuk membeli. Kualitas produk ditentukan oleh banyaknya kegunaan dan fungsi dari barang tersebut, termasuk seberapa lama produk tersebut berdaya guna, ketidakbergantungan pada produk lain, eksklusifitas, dan desain produk itu sendiri (warna, bentuk, kemasan dan sebagainya). Persepsi pembeli terhadap produk menjadi pertimbangan dalam memilih produk yang akan dibeli. Dengan kesadaran yang tinggi, konsumen menjadi tertarik, melakukan evaluasi serta menerima informasi yang diterimanya tentang produk tersebut. Untuk memberikan persepsi yang tepat kepada konsumen, perusahaan perlu terus memperhatikan metrik kualitas produk yang mereka tawarkan. Konsumen bisa melupakan apa yang telah mereka pelajari, tetapi cenderung mengingat informasi yang mendukung keyakinan mereka tentang suatu produk tertentu (Shiratina \& Afiatun, 2017).

Selain kualitas produk maupun persepsi konsumen, dalam memutuskan suatu pembelian, brand image sangat mempengaruhi seseorang dalam melakukan pembelian suatu produk. Apabila brand image yang dihasilkan positif maka di dalam pemikiran pembeli akan terbentuk hal positif terhadap image yang dihasilkan dan begitu juga sebaliknya. Dengan merek tersebut perusahan mengharapkan agar konsumen mempunyai kesan positif pada barangnya. Salah satu cara yang dapat dilakukan perusahaan dalam menghasilkan suatu keputusan konsumen yakni komunikasi word of mouth. Dengan demikian, komunikasi dari mulut ke mulut sangatlah efektif dalam memberikan informasi bagi konsumen.

Melihat fenomena tersebut diatas maka dapat dirumuskan permasalahan penelitian di antaranya adalah seberapa besar dampak kualitas produk, persepsi konsumen dan brand image terhadap keputusan pembelian melalui word of mouth terhadap produk yang dipromosikan oleh artis / selebriti melalui kegiatan endorsement. Tujuan dari penelitian ini adalah untuk mengetahui seberapa besar dampak kualitas produk, persepsi konsumen dan brand image terhadap keputusan pembelian produk endorsement pada masyarakat di Medan melalui word of mouth.

\section{LANDASAN TEORI Definisi}

Kualitas produk mempunyai hubungan yang sangat erat dengan sikap konsumen, dimana kualitas produk dapat menyajikan minat dan ketertarikan kepada pembeli untuk meningkatkan strong bonding perusahan. Dengan adanya kualitas produk yang baik inilah yang akan membuat para konsumen puas dan percaya. Lebih lanjut, masyarakat akan tertarik terhadap suatu produk karena sesuai dengan keinginan ataupun kebutuhan mereka (Martini, Feriyansyah, \& Venanza, 2021).

Persepsi adalah proses bagaimana stimuli-stimuli untuk pembelian suatu produk akan diseleksi, diorganisasikan dan diinterpretasikan (Syahputro, Lie, Butarbutar, \& Inrawan, 2015).

Ketika kita menjalankan bisnis, kita perlu memelihara dan membangun citra merek, produk, layanan, dan layanan yang dijual untuk menemukan tempat yang sesuai dengan konsumen. Hal ini mendorong berbagai pengusaha untuk membangun citra merek dari bisnis yang mereka geluti. Citra merek merupakan reaksi konsumen terhadap suatu 
merek berdasarkan kualitas merek tersebut. Merek yang diingat konsumen. Citra merek adalah keyakinan yang terbentuk dalam benak konsumen tentang subjek yang dirasakan dari produk (Kotler \& Armstrong, 2014).

Word of mouth adalah suatu kegiatan pemasaran yang dilakukan melalui perantara orang ke orang secara lisan, tulisan, dan jenis komunikasi lainnya yang didasari oleh pengalaman setelah membeli dan memakai produk tersebut (Ketler \& Keller, 2019).

Keputusan pembelian adalah tahap dalam proses pengambilan keputusan pembeli dimana konsumen benar-benar akan membeli suatu produk (Kotler \& Armstrong, 2014).

\section{Kerangka Konseptual}

Salah satu dari tujuh komponen yang ada mengenai keputusan pembelian adalah tentang jenis produk. Konsumen dapat membuat suatu keputusan untuk membeli sebuah barang atau jasa ketika ada kebutuhan dan keinginan terhadap produk tersebut. Kualitas produk yang diberikan perusahaan adalah strategi yang tepat untuk menarik perhatian konsumen (Dharmmesta \& Handoko, 2016).

Lebih lanjut, persepsi konsumen dapat dipengaruhi oleh faktor internal (ketertarikan dan kebutuhan, serta ekspektasi akan suatu produk) dan faktor eksternal (tampakan produk, sifat-sifat stimulus, dan situasi lingkungan). Untuk mengetahui mengapa konsumen menerima atau menolak suatu produk atau merek, perusahaan harus memperhatikan dengan sungguh-sungguh pandangan konsumen terhadap merek produk tersebut, meski pandangan tersebut sangat tidak masuk akal sekalipun. Hal ini memerlukan pengetahuan tentang dinamika persepsi manusia dan juga pengertian tentang aturan-aturan fisiologis dan psikologis yang menentukan seleksi, organisasi dan interpretasi dari stimulus sensorik.

Proses keputusan konsumen terjadi ketika individu berada pada pilihan antara membeli atau tidak membeli, memilih antara merek X atau merek $\mathrm{Y}$, atau membelanjakan barang $\mathrm{A}$ atau barang $\mathrm{B}$, maka individu tersebut dikatakan dalam keadaan proses pengambilan keputusan. Sementara itu pendapat Sernovitz dalam Joesyiana (2018), terdapat tiga motivasi dasar yang mendorong pembicaraan word of mouth, yaitu mereka yang menyukai suatu produk, adanya pembicaraan yang membuat konsumen merasa baik dan mereka yang merasa terhubung dalam suatu kelompok (Syahputro, Lie, Butarbutar, \& Inrawan, 2015).

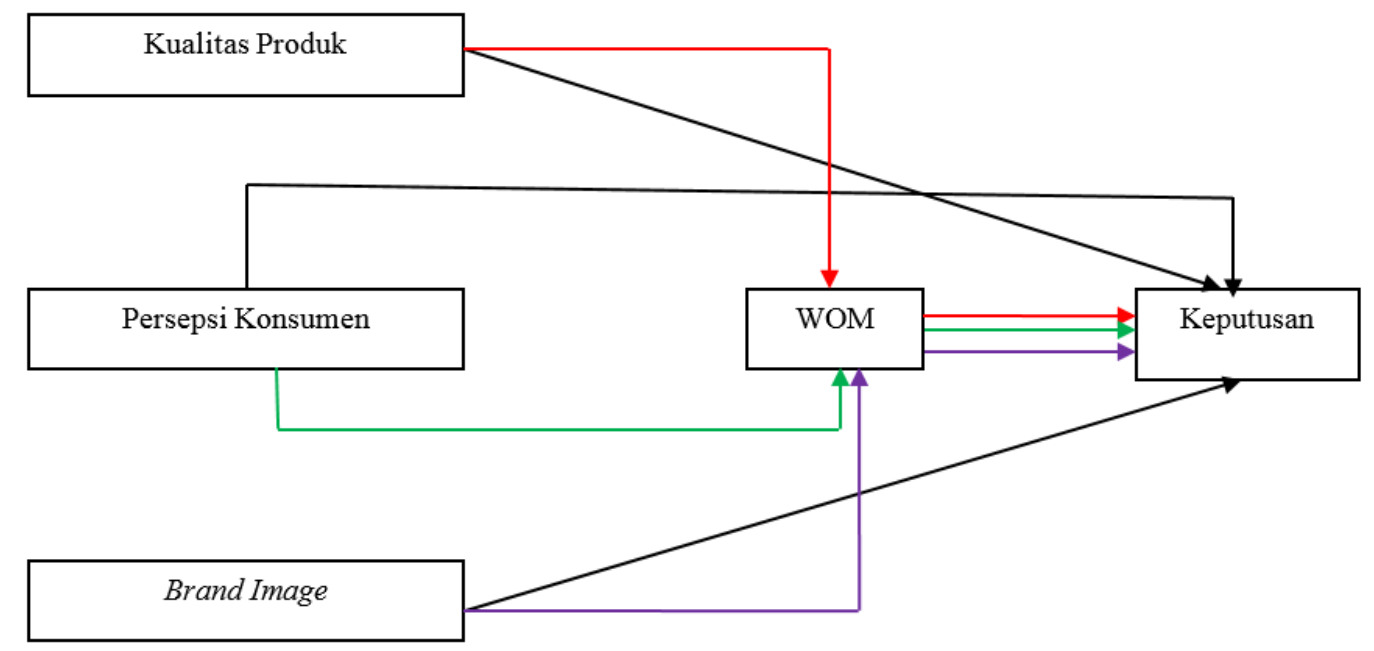




\section{Hipotesis Penelitian}

Yang menjadi hipotesis pada penelitian ini adalah:

$\mathrm{H}_{1} \quad$ Terdapat dampak kualitas terhadap keputusan pembelian produk endorsement pada masyarakat di Medan

$\mathrm{H}_{2}$ Terdapat dampak persepsi konsumen terhadap keputusan pembelian produk endorsement pada masyarakat di Medan

$\mathrm{H}_{3} \quad$ Terdapat dampak brand image terhadap keputusan pembelian produk endorsement pada masyarakat di Medan

$\mathrm{H}_{4} \quad$ Terdapat dampak kualitas produk terhadap keputusan pembelian produk endorsement melalui word of mouth pada masyarakat di Medan

$\mathrm{H}_{5} \quad$ Terdapat dampak persepsi konsumen terhadap keputusan pembelian produk endorsement melalui word of mouth pada masyarakat di Medan

$\mathrm{H}_{6} \quad$ Terdapat dampak brand image terhadap keputusan pembelian produk endorsement melalui word of mouth pada masyarakat di Medan

\section{METODOLOGI PENELITIAN}

Populasi pada penelitian ini adalah masyarakat yang berada di wilayah kota Medan yang pernah melakukan pembelian produk kue yang diiklankan secara endorsement oleh selebritis terkenal.

$\frac{N=Z^{2 \alpha / 2}}{4 e^{a}}$

Keterangan:

$\mathrm{N}=$ Jumlah sampel

$\alpha=$ tingkat kepercayaan dugaan $(\alpha=5 \%)$

$\mathrm{e}=$ Kesalahan dugaan $(\mathrm{e}=10 \%)$

$\mathrm{Z}=$ Nilai normal

Maka berdasarkan rumus diatas, sampel pada penelitian ini adalah:

$$
\begin{gathered}
\mathrm{N}=\frac{1,96^{2}}{4(0,1)^{2}} \\
=96,04
\end{gathered}
$$

Untuk keperluan penelitian ini maka digunakan 100 orang responden untuk memudahkan pengumpulan data.

Jenis data pada penelitian ini terdiri dari dua jenis yakni data primer yang diperoleh langsung dari sumber utama penelitian. Salah satu bagian dari jenis data primer adalah kuesioner yang disebarkan kepada responden. Sedangkan jenis data sekunder yaitu jenis data yang diperoleh dengan cara tidak langsung atau dengan kata lain data yang didapatkan dari pihak lain yang berupa literatur atau dokumen-dokumen di luar data primer. Pengumpulan data pada penelitian ini dilakukan menggunakan kuesioner sebagai instrumen. Adapun beberapa proses dalam pengumpulan data antara lain melakukan edit, pemberian kode, pemberian skor dan tabulasi.

Uji instrumen penelitian yang dimaksud pada penelitian yaitu kuesioner penelitian dengan melakukan uji validitas dan reliabilitas. Uji validitas adalah pengujian yang menunjukkan sejauh mana alat ukur yang dipergunakan mampu dalam mengukur apa yang kita ukur sehingga ukurannya valid. Uji validitas dinyatakan valid apabila signifikan 
$<0,05$ dan begitu juga sebaliknya. Sedangkan reliabilitas adalah tes untuk mengukur pernyataan-pernyataan yang merupakan indikator dari variabel yang dipakai dalam penelitian. Suatu kuesioner dikatakan reliabel atau handal jika respons seseorang terhadap pernyataan yang diberikan adalah konsisten dan tidak ada perubahan (Ghozali, 2018).

Teknik analisis data penelitian dengan menggunakan analisis jalur atau disebut juga dengan path analysis. Ghozali (2018) menjelaskan bahwa analisis jalur (path analysis) adalah dengan menggunakan analisis regresi untuk melihat hubungan kausalitas antar variabel yang telah ditetapkan sebelumnya. Dalam hal pengujian variabel yang bersifat memediasi maka digunakan pengujian selisih mutlak. Uji dari selisih mutlak yaitu untuk menguji moderasi dengan menggunakan model selisih mutlak dari variabel independen atau variabel bebas.

\section{HASIL PENELITIAN DAN PEMBAHASAN}

Uji instrumen pada penelitian ini menggunakan uji validitas dan reliabilitas yaitu pada uji valid dengan membandingkan rhitung dan rtabel sedangkan pada reliabilitas dapat diketahui dengan nilai Cronbach's Alpha. Apabila nilai Cronbach's Alpha di atas 0,6 maka dapat dinyatakan reliabel pada setiap item pertanyataan pada penelitian ini.

1. Uji Validitas dan Reliabilitas pada Variabel Kualitas Produk

Tabel 1. Uji Validitas dan Reliabilitas pada Variabel Kualitas Produk

\begin{tabular}{lll}
\hline & $\begin{array}{c}\text { Corrected Item-Total } \\
\text { Correlation }\end{array}$ & Cronbach's Alpha if Item Deleted \\
\hline $\mathrm{X} 1.1$ & .443 & .907 \\
\hline $\mathrm{X} 1.2$ & .346 & .914 \\
\hline $\mathrm{X} 1.3$ & .554 & .904 \\
\hline $\mathrm{X} 1.4$ & .586 & .903 \\
\hline $\mathrm{X} 1.5$ & .630 & .901 \\
\hline $\mathrm{X} 1.6$ & .743 & .898 \\
\hline $\mathrm{X} 1.7$ & .657 & .900 \\
\hline $\mathrm{X} 1.8$ & .633 & .901 \\
\hline $\mathrm{X} 1.9$ & .653 & .901 \\
\hline $\mathrm{X} 1.10$ & .583 & .903 \\
\hline $\mathrm{X} 1.11$ & .691 & .899 \\
\hline $\mathrm{X} 1.12$ & .602 & .902 \\
\hline $\mathrm{X} 1.13$ & .743 & .898 \\
\hline $\mathrm{X} 1.14$ & .505 & .905 \\
\hline $\mathrm{X} 1.15$ & .508 & .905 \\
\hline $\mathrm{X} 1.16$ & .689 & .899 \\
\hline Sumber: Olahan Data $(2021)$ & &
\end{tabular}

Pada Tabel 1 dapat diketahui dari 16 pernyataan pada kualitas produk dapat diketahui nilai dari corrected item total correlation diatas 0,3 dan nilai dari Cronbach's Alpha pada setiap item pernyataan diatas 0,6 maka dapat dinyatakan bahwa setiap item pernyataan pada kualitas produk dapat dinyatakan valid dan reliabel. 
2. Uji Validitas dan Reliabilitas pada Variabel Persepsi Konsumen

Tabel 2. Uji Validitas dan Reliabilitas pada Variabel Persepsi Konsumen

\begin{tabular}{lrr}
\hline & $\begin{array}{c}\text { Corrected Item-Total } \\
\text { Correlation }\end{array}$ & Cronbach's Alpha if Item Deleted \\
\hline X2.1 & .614 & .753 \\
\hline X2.2 & .351 & .815 \\
\hline X2.3 & .610 & .755 \\
\hline X2.4 & .577 & .762 \\
\hline X2.5 & .540 & .771 \\
\hline X2.6 & .654 & .746 \\
\hline
\end{tabular}

Sumber: Olahan Data (2021)

Pada Tabel 2 dapat diketahui dari 6 pernyataan pada persepsi konsumen dapat diketahui nilai dari corrected item total correlation diatas 0,3 dan nilai dari Cronbach's Alpha pada setiap item pernyataan diatas 0,6 maka dapat dinyatakan bahwa setiap item pernyataan pada persepsi konsumen dapat dinyatakan valid dan reliabel.

3. Uji Validitas dan Reliabilitas pada Variabel Brand Image

Tabel 3. Uji Validitas dan Reliabilitas pada Variabel Brand Image

\begin{tabular}{|c|c|c|}
\hline & $\begin{array}{l}\text { Corrected Item-Total } \\
\text { Correlation }\end{array}$ & Cronbach's Alpha if Item Deleted \\
\hline X3.1 & .673 & .709 \\
\hline $\mathrm{X} 3.2$ & .466 & .746 \\
\hline X3.3 & .395 & .758 \\
\hline X3.4 & .512 & .738 \\
\hline X3.5 & .471 & .745 \\
\hline X3.6 & .317 & .771 \\
\hline X3.7 & .402 & .756 \\
\hline X3.8 & .537 & .733 \\
\hline
\end{tabular}

Sumber: Olahan Data (2021)

Pada Tabel 3 dapat diketahui dari 8 pernyataan pada brand image dapat diketahui nilai dari corrected item total correlation diatas 0,3 dan nilai dari Cronbach's Alpha pada setiap item pernyataan diatas 0,6 maka dapat dinyatakan bahwa setiap item pernyataan pada brand image dapat dinyatakan valid dan reliabel. 
4. Uji Validitas dan Reliabilitas pada Variabel Word of Mouth

Tabel 4. Uji Validitas dan Reliabilitas pada Variabel Word of Mouth

\begin{tabular}{lrr}
\hline & Corrected Item-Total Correlation & Cronbach's Alpha if Item Deleted \\
\hline $\mathrm{Z} .1 .1$ & .633 & .873 \\
\hline $\mathrm{Z} 1.2$ & .659 & .871 \\
\hline $\mathrm{Z} 1.3$ & .758 & .864 \\
\hline $\mathrm{Z} 1.4$ & .643 & .873 \\
\hline $\mathrm{Z} 1.5$ & .737 & .866 \\
\hline $\mathrm{Z} 1.6$ & .545 & .880 \\
\hline $\mathrm{Z} 1.7$ & .597 & .876 \\
\hline $\mathrm{Z} 1.8$ & .484 & .884 \\
\hline $\mathrm{Z} 1.9$ & .568 & .878 \\
\hline $\mathrm{Z} 1.10$ & .575 & .877 \\
\hline
\end{tabular}

Sumber: Olahan Data (2021)

Pada Tabel 4 dapat diketahui dari 10 pernyataan pada word of muouth dapat diketahui nilai dari corrected item total correlation diatas 0,3 dan nilai dari Cronbach's Alpha pada setiap item pernyataan diatas 0,6 maka dapat dinyatakan bahwa setiap item pernyataan pada word of muouth dapat dinyatakan valid dan reliabel.

5. Uji Validitas dan Reliabilitas pada Variabel Keputusan Pembelian Tabel 5. Uji Validitas dan Reliabilitas pada Variabel Keputusan Pembelian Corrected Item-Total Correlation Cronbach's Alpha if Item Deleted

\begin{tabular}{|c|c|c|}
\hline & Correlation & Cronbach's Alpha if Item Deleted \\
\hline Y1.1 & .663 & .903 \\
\hline $\mathrm{Y} 1.2$ & .785 & .892 \\
\hline $\mathrm{Y} 1.3$ & .830 & .889 \\
\hline Y1.4 & .747 & .896 \\
\hline Y1.5 & .772 & .894 \\
\hline Y1.6 & .770 & .894 \\
\hline Y1.7 & .523 & .915 \\
\hline Y1.8 & .608 & .908 \\
\hline
\end{tabular}

Sumber: Olahan Data (2021)

Pada Tabel 5 dapat diketahui dari 8 pernyataan pada keputusan pembelian dapat diketahui nilai dari corrected item total correlation diatas 0,3 dan nilai dari Cronbach's Alpha pada setiap item pernyataan diatas 0,6 maka dapat dinyatakan bahwa setiap item pernyataan pada keputusan pembelian dapat dinyatakan valid dan reliabel.

Berikut adalah pembuktian hipotesis yang telah di rumuskan pada penelitian ini yaitu sebagai berikut:

Tabel 6. Dampak Kualitas Produk Terhadap Keputusan Pembelian

\begin{tabular}{|c|c|c|c|c|c|}
\hline \multirow[t]{2}{*}{ Variabel } & $\begin{array}{r}\text { Unstan } \\
\text { Coeff }\end{array}$ & $\begin{array}{l}\text { dized } \\
\text { ents }\end{array}$ & $\begin{array}{l}\text { Standardized } \\
\text { Coefficients }\end{array}$ & \multirow[t]{2}{*}{$\mathrm{t}$} & \multirow[t]{2}{*}{ Sig. } \\
\hline & B & $\begin{array}{l}\text { Std. } \\
\text { Error }\end{array}$ & Beta & & \\
\hline Kualitas Produk & .174 & .078 & .345 & 2.238 & .028 \\
\hline
\end{tabular}

Sumber: Olahan Data (2021) 
Berdasarkan pada Tabel 6 dampak kualitas produk terhadap keputusan pembelian produk di Medan, bahwa dengan menunjukkan nilai koefisien beta sebesar 0,345 dengan nilai $t$ hitung sebesar 2.238 dan table sebesar 1,66105 atau (tcount > ttable) maka kualitas produk berpengaruh terhadap keputusan pembelian produk di Medan.

Tabel 7. Dampak Persepsi Konsumen Terhadap Keputusan Pembelian

\begin{tabular}{|c|c|c|c|c|c|}
\hline \multirow[t]{2}{*}{ Variabel } & \multicolumn{2}{|c|}{$\begin{array}{c}\text { Unstandardized } \\
\text { Coefficients }\end{array}$} & \multirow{2}{*}{$\begin{array}{c}\begin{array}{c}\text { Standardized } \\
\text { Coefficients }\end{array} \\
\text { Beta } \\
\end{array}$} & \multirow[t]{2}{*}{$\mathrm{t}$} & \multirow[t]{2}{*}{ Sig. } \\
\hline & B & $\begin{array}{l}\text { Std. } \\
\text { Error }\end{array}$ & & & \\
\hline Persepsi Konsumen & .505 & .219 & .380 & 2.306 & .023 \\
\hline
\end{tabular}

Berdasarkan pada Tabel 7 dampak persepsi konsumen terhadap keputusan pembelian produk di Medan, bahwa dengan menunjukkan nilai koefisien beta sebesar 0,380 dengan nilai t hitung sebesar 2.306 dan ttable sebesar 1,66105 atau (tcount > ttable) maka persepsi konsumen berpengaruh terhadap keputusan pembelian produk di Medan.

Tabel 8. Dampak Brand Image Terhadap Keputusan Pembelian

\begin{tabular}{|c|c|c|c|c|c|}
\hline \multirow[t]{2}{*}{ Variabel } & \multicolumn{2}{|c|}{$\begin{array}{c}\text { Unstandardized } \\
\text { Coefficients }\end{array}$} & $\begin{array}{l}\text { Standardized } \\
\text { Coefficients }\end{array}$ & \multirow[t]{2}{*}{$\mathrm{t}$} & \multirow[t]{2}{*}{ Sig. } \\
\hline & B & $\begin{array}{l}\text { Std. } \\
\text { Error }\end{array}$ & Beta & & \\
\hline Brand Image & .260 & .118 & .261 & 2.204 & .030 \\
\hline
\end{tabular}

Berdasarkan pada Tabel 8 dampak brand image terhadap keputusan pembelian produk di Medan, bahwa dengan menunjukkan nilai koefisien beta sebesar 0,261 dengan nilai t hitung sebesar 2.204 dan ttable sebesar 1,66105 atau (tcount > ttable) maka brand image berpengaruh terhadap keputusan pembelian produk di Medan.

Koefisien regresi menjelaskan seberapa besar dampak keputusan pembelian dalam menjelaskan kualitas produk, persepsi konsumen dan brand image:

\section{Tabel 9. Koefisien Korelasi}

\begin{tabular}{lrrrr}
\hline Model & R & R Square & Adjusted R Square & Std. Error of the Estimate \\
\hline 1 & $.980^{\mathrm{a}}$ & .961 & .960 & .66369 \\
\hline a. Predictors: (Constant), Brand Image, Kualitas Produk, Persepsi Konsumen
\end{tabular}

Berdasarkan pada Tabel 9 koefisien korelasi di dapatkan nilai dari korelasi sebesar 0,961 atau $96,1 \%$ yang artinya bahwa keputusan pembelian dapat dijelaskan oleh kualitas produk, persepsi konsumen dan brand image sebesar 96,1\% sedangkan sisanya dipengaruhi oleh faktor lain yang tidak diteliti dalam penelitian ini. 
Tabel 10. Kualitas Produk Terhadap Keputusan Pembelian Melalui Word of Mouth

\begin{tabular}{llllrrr}
\hline & \multicolumn{2}{c}{ Unstandardized Coefficients } & Standardized Coefficients & & \\
\cline { 2 - 4 } Model & \multicolumn{1}{c}{ B } & \multicolumn{1}{c}{ Std. Error } & Beta & \multicolumn{1}{c}{ S } & Sig. \\
\hline 1 (Constant) & 33.971 & .103 & & & 329.888 & .000 \\
Zscore: Kualitas Produk & 2.994 & .319 & .902 & 9.379 & .000 \\
Zscore: Word of Mouth & .247 & .315 & .074 & .786 & .434 \\
ModerasiX1 & -.184 & .437 & -.010 & -.421 & .674 \\
\hline
\end{tabular}

a. Dependent Variable: Keputusan Pembelian

Sumber: Olahan Data (2021)

Berdasarkan pada hasil pemoderasi didapatkan bahwa word of mouth didapatkan nilai koefisien sebesar -0.184 dengan nilai signifikansi sebesar $0.674>0.05$ maka dapat dinyatakan bahwa word of mouth tidak dapat memoderasi dampak atau hubungan kualitas produk terhadap keputusan pembelian produk di Medan.

Tabel 11. Persepsi Konsumen Terhadap Keputusan Pembelian Melalui Word of Mouth

\begin{tabular}{lllrrrr}
\hline & \multicolumn{3}{c}{ Unstandardized Coefficients Standardized Coefficients } & & \\
\cline { 2 - 4 } Model & \multicolumn{1}{c}{ B } & Std. Error & Beta & \multicolumn{1}{c}{ S } & Sig. \\
\hline 1 (Constant) & 34.083 & .104 & & & 327.007 & .000 \\
Zscore: Persepsi Konsumen & 3.164 & .315 & & .954 & 10.041 & .000 \\
Zscore: Word of Mouth & .054 & .312 & .016 & .172 & .864 \\
ModerasiX2 & -.853 & .463 & -.041 & -1.843 & .068 \\
\hline
\end{tabular}

a. Dependent Variable: Keputusan Pembelian

Sumber: Olahan Data (2021)

Berdasarkan pada hasil pemoderasi didapatkan bahwa word of mouth didapatkan nilai koefisien sebesar 0,853 dengan nilai signifikansi sebesar $-1.843>0.05$ maka dapat dinyatakan bahwa word of mouth tidak dapat memoderasi dampak atau hubungan persepsi konsumen terhadap keputusan pembelian produk di Medan.

Tabel 12. Brand Image Terhadap Keputusan Pembelian Melalui Word of Mouth

\begin{tabular}{|c|c|c|c|c|c|c|}
\hline \multirow[b]{2}{*}{ Model } & \multicolumn{2}{|c|}{ Unstandardized Coefficients } & \multicolumn{2}{|c|}{ Standardized Coefficients } & \multirow[b]{2}{*}{$\mathrm{t}$} & \multirow[b]{2}{*}{ Sig. } \\
\hline & $\mathrm{B}$ & Std. Error & Beta & & & \\
\hline 1 (Constant) & 34.281 & .087 & & & 392.713 & .000 \\
\hline Zscore: Brand Image & 2.701 & .232 & & .814 & 11.631 & .000 \\
\hline Zscore: Word of Mouth & .549 & .232 & & .166 & 2.364 & .020 \\
\hline ModerasiX3 & 1.800 & .309 & & .116 & 5.833 & .000 \\
\hline
\end{tabular}

a. Dependent Variable: Keputusan Pembelian

Sumber: Olahan Data (2021)

Berdasarkan pada hasil pemoderasi didapatkan bahwa word of mouth didapatkan nilai koefisien sebesar 1.800 dengan nilai signifikansi sebesar $0.000<0.05$ maka dapat dinyatakan bahwa word of mouth dapat memoderasi dampak atau hubungan brand image terhadap keputusan pembelian produk endorsement di Medan.

1. Dampak Kualitas terhadap Keputusan Pembelian Produk Endorsement

Berdasarkan dari hasil pengujian hipotesis didapatkan bahwa kualitas produk berpengaruh terhadap keputusan pembelian produk endorsement di Medan, sedangkan 
dari hasil korelasi didapatkan sebesar 0.96 atau $96 \%$ yang memiliki arti bahwa keputusan pembelian mampu dijelaskan oleh kualitas produk sebesar 96\%. Hal ini sejalan dengan hasil penelitian yang telah dilakukan oleh Fatmawati dan Soliha bahwa kualitas produk berpengaruh terhadap keputusan pembelian (Fatmawati \& Soliha, 2017).

2. Dampak Persepsi Konsumen terhadap Keputusan Pembelian Produk Endorsement Berdasarkan dari hasil pengujian hipotesis didapatkan bahwa persepsi konsumen berpengaruh terhadap keputusan pembelian produk di Medan, sedangkan dari hasil korelasi didapatkan sebesar 0.96 atau $96 \%$ yang memiliki arti bahwa keputusan pembelian mampu dijelaskan oleh persepsi konsumen sebesar 96\%., hal ini sejalan dengan hasil penelitian yang telah dilakukan oleh Sardanto dan Ratnanto dengan hasil penelitian persepsi konsumen berpengaruh terhadap keputusan (Sardanto \& Ratnanto, 2016).

3. Dampak Brand Image terhadap Keputusan Pembelian Produk Endorsement Berdasarkan dari hasil pengujian hipotesis didapatkan bahwa brand image berpengaruh terhadap keputusan pembelian produk di Medan, sedangkan dari hasil korelasi didapatkan sebesar 0.96 atau $96 \%$ yang memiliki arti bahwa keputusan pembelian mampu dijelaskan oleh brand image sebesar 96\%., hal ini sejalan dengan hasil penelitian yang telah dilakukan oleh Atmaja dan Menuh bahwa brand image berpengaruh terhadap keputusan pembelian (Atmaja \& Menuh, 2019).

4. Dampak Kualitas Produk terhadap Keputusan Pembelian Produk Endorsement melalui Word of Mouth

Hasil dari pengujian hipotesis dengan menghasilkan bahwa word of mouth tidak dapat memediasi antara kualitas produk dengan keputusan pembelian, dengan tingkat signifikansi diatas 0.05 . hal ini bertolak belakang dengan hasil penelitian yang dilakukan oleh Astaki dan Purnami dengan hasilnya bahwa word of mouth dapat memediasi kualitas produk terhadap keputusan pembelian. Salah satu yang dapat menyebabkan word of mouth tidak dapat memediasi kualitas produk terhadap keputusan, bahwasanya produk, salah satu kue khas medan yang di promosikan oleh artis Indonesia, disebabkan karena artis yang mempromosikan kue tersebut otomatis kue tersebut memiliki hasil dan kualitas yang baik di antara kue yang sejenis sehingga tanpa adanya promosi dari mulut ke mulut pembeli tetap membeli produk tersebut (Astaki \& Purnami, 2019).

5. Dampak Persepsi Konsumen terhadap Keputusan Pembelian Produk Endorsement melalui Word of Mouth

Hasil dari pengujian hipotesis dengan menghasilkan bahwa word of mouth tidak dapat memediasi antara persepsi konsumen dengan keputusan pembelian, dengan tingkat signifikansi diatas 0.05. Hal yang disebabkan bahwa word of mouth tidak dapat memediasi persepsi konsumen dengan keputusan pembelian, dikarenakan bahwa produk endorsement merupakan salah satu konsep kekinian. Apabila kue tersebut pernah di promosikan oleh salah satu artis Indonesia yang sangat terkenal di Indonesia, dengan di promosikan oleh artis tersebut maka secara tidak langsung akan membentuk persepsi konsumen dengan sendirinya tanpa harus melakukan promosi dari mulut ke mulut.

6. Dampak Brand Image terhadap Keputusan Pembelian Produk Endorsement melalui Word of Mouth

Hasil dari pengujian hipotesis dengan menghasilkan bahwa word of mouth dapat memediasi antara brand image dengan keputusan pembelian, dengan tingkat signifikansi dibawah 0.05 . Hal yang menyebabkan bahwa word of mouth dapat melakukan mediasi antara brand image dengan keputusan pembelian dikarenakan bahwa telah atau pernah di promosikan oleh artis salah satu Indonesia, dengan di promosikan oleh artis Indonesia akan dapat membentuk image masyarakat secara otomatis dengan menganggap bahwa 
kue tersebut kuenya atau usaha artis, sehingga memiliki dampak dalam hal keputusan pembelian.

\section{KESIMPULAN}

Sebagai penutup dari penelitian ini maka dapa diambil beberapa kesimpulan yaitu (1) kualitas produk berpengaruh terhadap keputusan pembelian produk endorsement pada masyarakat di Medan (2) persepsi konsumen berpengaruh terhadap keputusan pembelian produk endorsement pada masyarakat di Medan (3) brand image berpengaruh terhadap keputusan pembelian produk endorsement pada masyarakat di Medan (4) word of mouth tidak memoderasi kualitas produk terhadap keputusan pembelian produk endorsement pada masyarakat di Medan (5) word of mouth tidak memoderasi persepsi konsumen terhadap keputusan pembelian produk endorsement pada masyarakat di Medan dan (6) word of mouth memoderasi brand image terhadap keputusan pembelian produk endorsement pada masyarakat di Medan.

\section{DAFTAR PUSTAKA}

Astaki, N. P., \& Purnami, N. (2019). Peran Word of Mouth Memediasi Kualitas Produk Terhadap Keputusan Pembelian Konsumen. E-Jurnal Manajemen. Retrieved from https://doi.org/10.24843/EJMUNUD.2019.v08.i09.p05

Atmaja, N. D., \& Menuh, N. (2019). Peran Mediasi Brand Trust pada Pengaruh Brand Image Terhadap Keputusan Pembelian secara Online. Meningkatkan Mutu Penelitian dan Peringkat Perguruan Tinggi. Denpasar: STIMI Handayani.

Dharmmesta, B. S., \& Handoko, T. (2016). Manajemen Pemasaran Analisis Perilaku Konsumen. BPFE Yogyakarta.

Fatmawati, N., \& Soliha, E. (2017). Kualitas Produk, Citra Merek dan Persepsi Harga terhadap Proses Keputusan Pembelian Konsumen Sepeda Motor Matic "HONDA". Jurnal Manajemen Teori dan Terapan, Universitas Airlangga. Retrieved from http://dx.doi.org/10.20473/jmtt.v10i1.5134

Ghozali, I. (2018). BUKU APLIKASI ANALISIS MULTIVARIATE DENGAN PROGRAM IBM SPSS 25. Badan Penerbit Universitas Diponegoro.

Ketler, P., \& Keller, K. L. (2019). Manajemen Pemasaran. Erlangga.

Kotler, P., \& Armstrong, G. (2014). Principles of Marketing. Pearson.

Martini, A. N., Feriyansyah, A., \& Venanza, S. (2021). Pengaruh Kualitas Produk terhadap Keputusan Pembelian Handphone Oppo di Kota Pagar Alam. Jurnal Aktiva: Riset Akuntansi dan Keuangan. Retrieved from https://doi.org/10.52005/aktiva.v2i3.82

Sardanto, R., \& Ratnanto, S. (2016). Pengaruh Persepsi Konsumen terhadap Keputusan Pembelian pada Angkringan Kota Kediri. Jurnal Benefit. Retrieved from https://journal.unita.ac.id/index.php/benefit/article/view/89

Shiratina, A., \& Afiatun, P. (2017). Pengaruh Persepsi Konsumen dan Motivasi Konsumen terhadap Keputusan Pembelian Produk Kain Rajut (Studi Kasus CV Sinar Agung). Jurnal Riset Bisnis dan Manajemen. doi:10.34010/JURISMA.V7I1.472

Syahputro, D., Lie, D., Butarbutar, M., \& Inrawan, A. (2015). Pengaruh Persepsi Konsumen terhadap Keputusan Pembelian pada CV. Harmoni Lestari Pematangsiantar. Jurnal Sultanist. Retrieved from https://doi.org/10.37403/sultanist.v3i1.39 